\title{
Cell Division and Photosynthetic Apparatus Construction in the Cell Envelope Deficient 'Phofil' Mutant of Rhodopseudomonas sphaeroides
}

\author{
By JACQUES PRADEL AND JENNY CLEMENT-METRAL \\ Laboratoire de Photosynthèse, CNRS, Gif-sur-Yvette 9I 190, France and \\ Laboratoire de Biochimie Végétale, Université Aix, Marseille 13288, France
}

(Received I 8 April 1977)

The 'Phofil' mutant of Rhodopseudomonas sphaeroides showed a disturbed adaptation with respect to a change from aerobic to photosynthetic conditions. The mutation was a pleiotropic one: firstly, the cells formed multinucleate filaments with occasional septa, and secondly, they integrated only a fraction of the synthetized pigments. The phenotypes appeared in photosynthetic conditions during a period of unbalanced growth (unadapted state) followed by balanced exponential growth where the phenotypes were corrected (adapted state). Ultraviolet light irradiation or exposure to low temperature, but not partial or total depigmentation, caused adapted cells to return to the unadapted state. Except for those associated with pigments, no appreciable defect in the polypeptide composition of the cell envelope was detected by SDS-polyacrylamide gel electrophoresis. However, the protein/phospholipid ratio of the envelope fraction was approximately $50 \%$ higher, in the mutant than in the parent. These findings, and others described in the text, suggested the existence of defects in the cell wall and in the inner membrane.

\section{INTRODUCTION}

Most Rhodospirillaceae grow photosynthetically as well as chemotrophically (Oelze \& Drews, 1972; Cohen-Bazire, Sistrom \& Stanier, 1957). The development of the photosynthetic apparatus located on a membrane system is controlled by light, and, more importantly, by the degree of aerobiosis. Under low aeration conditions in the dark, with no light-dependent energy available, the bacteria contain a photosynthetic intracytoplasmic membrane. Thus, when aerobically-grown cells are made anaerobic in the light or semiaerobic in the dark, differentiation of the membrane occurs during an adaptation phase (Saunders \& Jones, 1974) simultaneously with the construction of the photosynthetic apparatus.

Recent reports have provided new information on this adaptation process, particularly on the multi-step assembly of photopigments in the developing membrane (Oelze \& Pahlke, 1976; Niederman, Mallon \& Langan, 1976). Several aspects of this process, however, are poorly understood, especially those concerning the initial stages of the induction of the photosynthetic membrane system (Peters \& Cellarius, 1972; Niederman et al., 1976). A convenient approach to the study of this problem was by the use of mutants defective in the adaptation process. Such mutants were mainly photosynthetically incompetent strains; only two, which retained the ability to synthetize bacteriochlorophyll at a decreased rate, have been studied (Uspenskaya \& Lyskova, I972; Drews, 1974). The 'Phofil' mutant isolated in this laboratory (Pradel \& Clément-Métral, 1976) was also aberrant in its adaptation to photosynthetic growth. Its physiological properties and the nature of the biochemical defects are reported here. 


\section{METHODS}

Organisms and culture conditions. Wild-type Rhodopseudomonas sphaeroides (strain Y) and the derived 'Phofil' mutant were used. A synthetic medium equally suitable for aerobic and photosynthetic growth (Jolchine \& Reiss-Husson, 1974) was used and solidified, when necessary, with I.5\% (w/v) agar (Difco). Unless indicated otherwise, the bacteria were grown at $30{ }^{\circ} \mathrm{C}$, with magnetic stirring, in glass bottles ( 1 and $100 \mathrm{ml}$ ). Photosynthetic cultures were bubbled with nitrogen and illuminated with incandescent bulbs (5000 lx). Aerobic cultures were grown either in the light and sparged with air or in the dark sparged with oxygen. Semi-aerobiosis was obtained by gassing with $\mathrm{O}_{2} / \mathrm{N}_{2}(5: 95, v i v)$ or by incubating in Erlenmeyer flasks on a low-speed shaker. The cell density was estimated by measuring $E_{1200}^{1} \mathrm{~cm}$ or by determining the number of viable cells.

Microscopy. A Zeiss microscope with phase-contrast illumination was used. Bacterial nucleoids were visualized using a low-sensitivity film and a long exposure time.

Ultraviolet light irradiation. Philips lamps (TUV) placed in a glove-box were used. The exposure was determined with a Latarjet ultraviolet light dosimeter (Latarjet, Morenne \& Berger, 1953).

Cell envelope isolution and purification. The method of Takemoto \& Lascelles (1973) was employed with the following modifications. To remove the ribosomes the membrane fraction was suspended in $30 \%(w \mathrm{v})$ $\mathrm{CsCl}$ and centrifuged at $350000 \mathrm{~g}$ for $60 \mathrm{~min}$. The ribosome-free envelope fraction was then collected, washed and layered on a discontinuous density gradient of Ficoll.

The method of Laemmli (1970) as modified by Clayton \& Haselkorn (1972) was used for sodium dodecyl sulphate (SDS)-polyacrylamide gel electrophoresis. The stained gels were scanned at $550 \mathrm{~nm}$ on a Safas $3000 \mathrm{D}$ spectrophotometer equipped with a linear transport device.

Analytical procedures. Bacteriochlorophyll was determined in the acetone/methanol $(7: 2, v / v)$ extract using $\epsilon_{770}=76 \times \mathrm{IO}^{-6} \mathrm{l} \mathrm{mol} \mathrm{mol}^{-1} \mathrm{~cm}^{-1}$ (Clayton, 1963). 4-Vinylprotochlorophyllide was determined as described previously (Pradel \& Clément-Métral, 1976). Lipids were extracted with chloroformimethanol (2:1, $\mathrm{v} / \mathrm{v}$ ) by the method of Bligh and Dyer as modified by Kates (1972). Total phosphorus was determined by the method of Bartlett (1959). Protein was estimated according to Lowry et al. (195I) with bovine serum albumin as standard.

\section{RESULTS}

\section{Physiological observations}

Isolation and phenotype. The mutant studied was isolated (Pradel \& Clément-Métral, 1976) as a green colony of normal size after aerobic growth; under photosynthetic growth conditions, the mutant colonies were markedly smaller than those of the wild type. The relatively slow growth of the mutant in photosynthetic conditions was used to test its genetic stability in terms of reversion frequency. Mutant cells previously bleached by aerobic growth in the light, were plated and grown photosynthetically. The revertant cells appeared as purple points on a greenish background. When $6 \times 10^{7}$ mutant cells were plated, 30 revertants were obtained. The reliability of this method was confirmed in a reconstruction test by counting the purple points on Petri dishes plated with a mixture of $10^{2}$ wild-type and $10^{6}$ mutant cells.

The green colour was due to overproduction and excretion of a bacteriochlorophyll precursor complex. Microscopic examination revealed that in photosynthetic conditions the bacteria formed filaments of variable lengths with occasional septa (Fig. $1 a$ ), and with general swelling and local bulging (Fig. I $b$ ).

Growth characteristics. Growth of the mutant strain was followed under extreme conditions: either in the dark at high partial pressure of oxygen or anaerobically in the light (the cells were pre-cultivated semi-aerobically). In aerobic conditions the lag phase was very short. In photosynthetic conditions it was very long; the doubling time, initially about $12 \mathrm{~h}$, decreased progressively to $100 \mathrm{~min}$ during exponential growth. We shall hereafter describe the mutant cells during the long lag phase as 'unadapted' (to photosynthesis), in contrast to 'adapted' cells which grow exponentially under anaerobic conditions in the light.

Growth and pigmentation. (i) Adapted mutant. After adaptation, the mutant strain had corrected both phenotypes; septation and cell division occurred at a normal rate, and all the pigmeni synthetized was integrated into the photosynthetic apparatus. Growth and pig- 

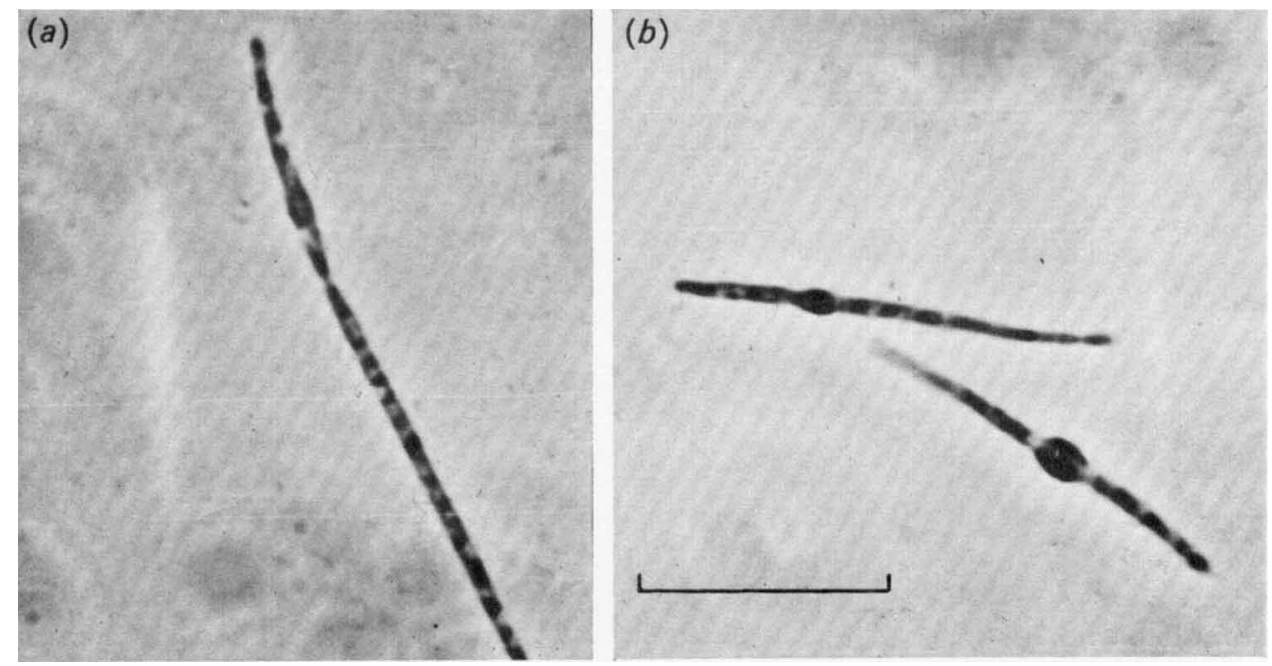

Fig. 1. Phase-contrast micrographs showing (a) nuclear bodies in filaments of $R$. sphaeroides 'Phofil' mutant grown in photosynthetic conditions, $(b)$ structural anomalies. Bar marker represents $25 \mu \mathrm{m}$.
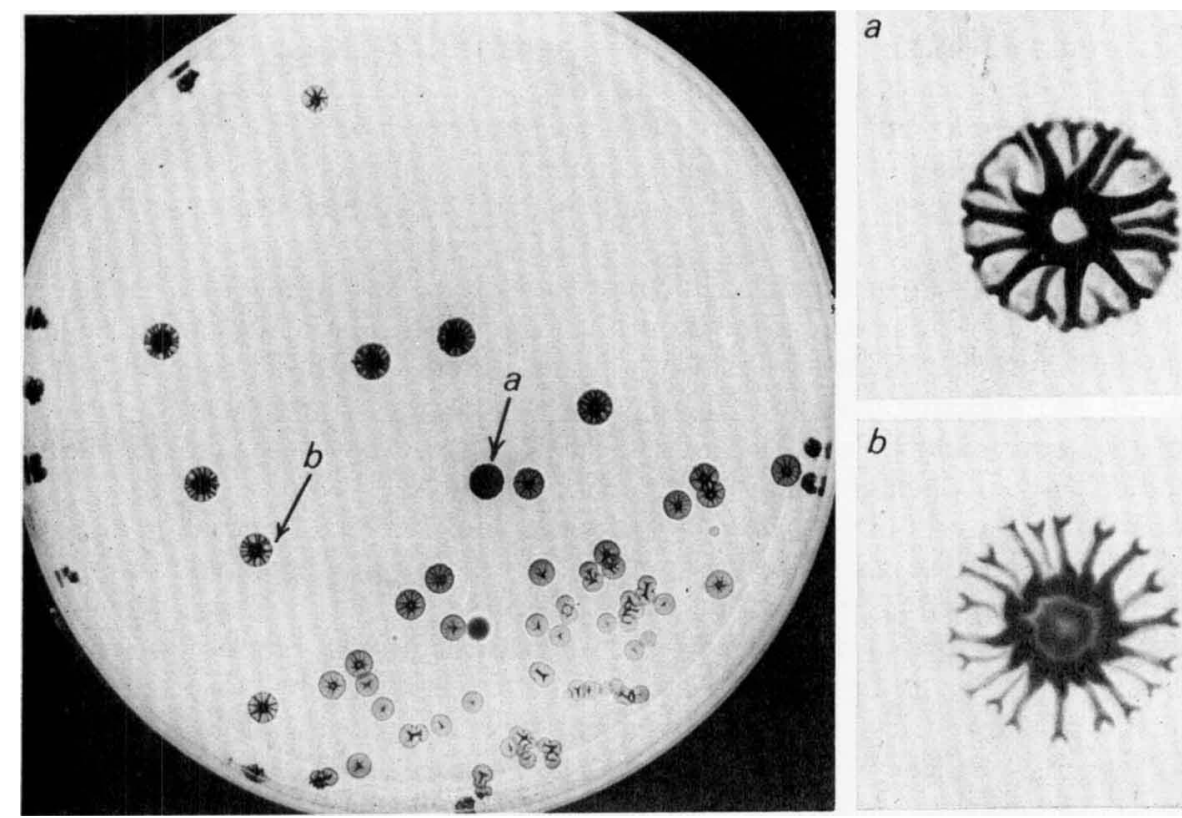

$b$

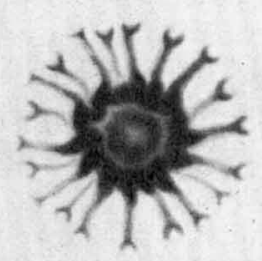

Fig. 2. Colonies from adapted cells of $\boldsymbol{R}$. sphaeroides 'Phofil' mutant grown semi-aerobically at $24^{\circ} \mathrm{C}$. The enlargements of colonies $a$ and $b$ are at $8 \times$ magnification.

mentation under photosynthetic conditions were temperature dependent. The mutant and parent strain had similar growth rates and cellular bacteriochlorophyll concentrations at temperatures above $30^{\circ} \mathrm{C}$ (Table I), but the effect of low temperature was more pronounced in the mutant. After aerobic growth on solid medium at temperatures above $30^{\circ} \mathrm{C}$, the colonies of both strains were identical. At lower temperatures, however, the mutant colonies were unusually crystalloid (Fig. 2) and were composed of two types of cell, some identical to wild-type cells and others forming short filaments. 
Table I. Temperature dependence of growth rates and bacteriochlorophyll concentrations in the adapted mutant and the wild type

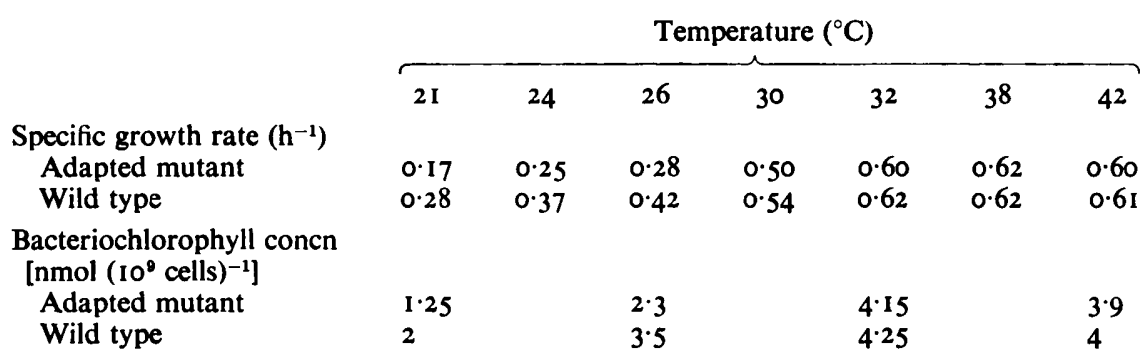

(ii) Unadapted mutant. Pigment synthesis capacity was not affected in the mutant as was shown earlier by the calculation of differential rates of pigment synthesis (Pradel \& ClémentMétral, 1976). Growth and pigmentation in photosynthetic conditions were studied throughout the adaptation phase (Fig. 3). The bacterial concentration was maintained, by successive dilutions of the culture, below a level corresponding to the yield of the wild type at the end of the exponential phase $\left(\mathrm{I} \cdot 5 \times 10^{9}\right.$ cells $\left.\mathrm{ml}^{-1}\right)$. The homogeneity of the culture was regularly checked by plating out. At the beginning of adaptation the bacteria grew very slowly and a growth rate could be determined between two dilutions. As growth proceeded, the growth rate increased (Fig. 3, part C), but towards the end of the adaptation process, constant growth rates could no longer be determined (Fig. 3, part B). Truly exponential growth was then established (Fig. 3, part A); the cells were adapted. The concentration of intracellular bacteriochlorophyll followed the same pattern as the growth rate, i.e. it increased progressively during adaptation. As the rate of pigment synthesis (bacteriochlorophyll+ precursor) did not change, the precursor was excreted at a rate which decreased throughout adaptation.

Colonies from inocula plated out at different times were homogeneous in appearance. Nevertheless their colour changed throughout the experiment. Plating out at the beginning of the adaptation process yielded colonies which were green due to the pigment precursor accumulating and diffusing deep into the agar. The colour was progressively lost as the leakage of pigment precursor decreased. At the end of the experiment, the colonies were purple, and crystalloid when grown at low temperature $\left(26^{\circ} \mathrm{C}\right)$.

In aerobic conditions, but under low partial pressure of oxygen, the leakage of pigment precursor depended on the physiological state of the cells; in the unadapted state leakage was severe but in adapted cells it did not occur. The growth rate, however, remained the same and was similar to that of the wild type, whereas the growth rate of unadapted cells grown anaerobically in the light was reduced due to the relatively low bacteriochlorophyll content which restricts the photochemical activity and therefore the utilizable energy.

Pigment precursor excretion and filament formation. Both phenotypic expressions were studied simultaneously to see whether they were caused by a single pleiotropic mutation or a double mutation. The mutant could correct the leakage of pigment precursor both aerobically, with a high partial pressure of oxygen, and when the cells were adapted to photosynthesis. In either case division proceeded normally, the mutant cells being essentially the same size as the wild type.

When an inoculum was precultivated aerobically and transferred to semi-aerobic and then to photosynthetic growth conditions, the cells became elongated when pigment synthesis occurred, i.e. long filaments were obtained in anaerobiosis in the light (Fig. 4). The reverse process, i.e. the recovery of normal cell division by unadapted mutant cells after inhibition of pigment synthesis, was also observed. Likewise, we noted that during 


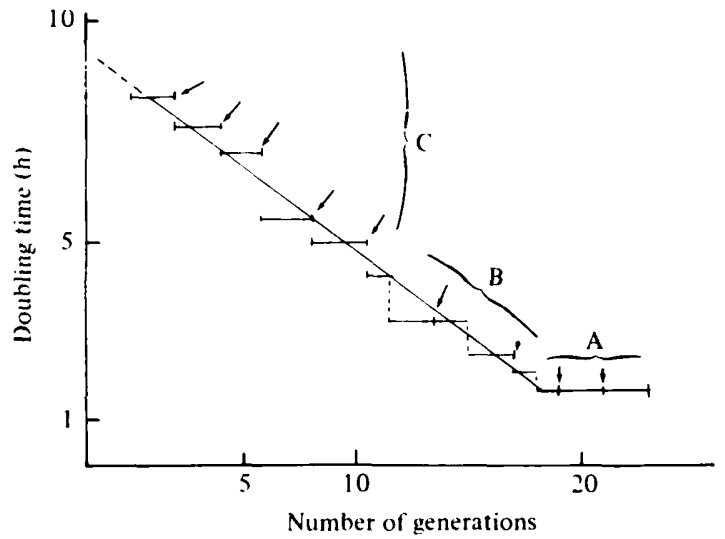

Fig. 3. Growth of $R$. sphaeroides 'Phofil' mutant in photosynthetic conditions at $30^{\circ} \mathrm{C}$ showing decrease of the doubling time with the number of generations. Arrows indicate the successive dilutions with fresh medium. A, Truly exponential growth; B and C, unadapted cells in lag phase. The initial dashed line illustrates the difficulty in defining, in phototrophy, a limit for the unadapted state. In such a state, mutant cells would be photosynthetically incompetent since all the pigments are excreted as pigment precursor.
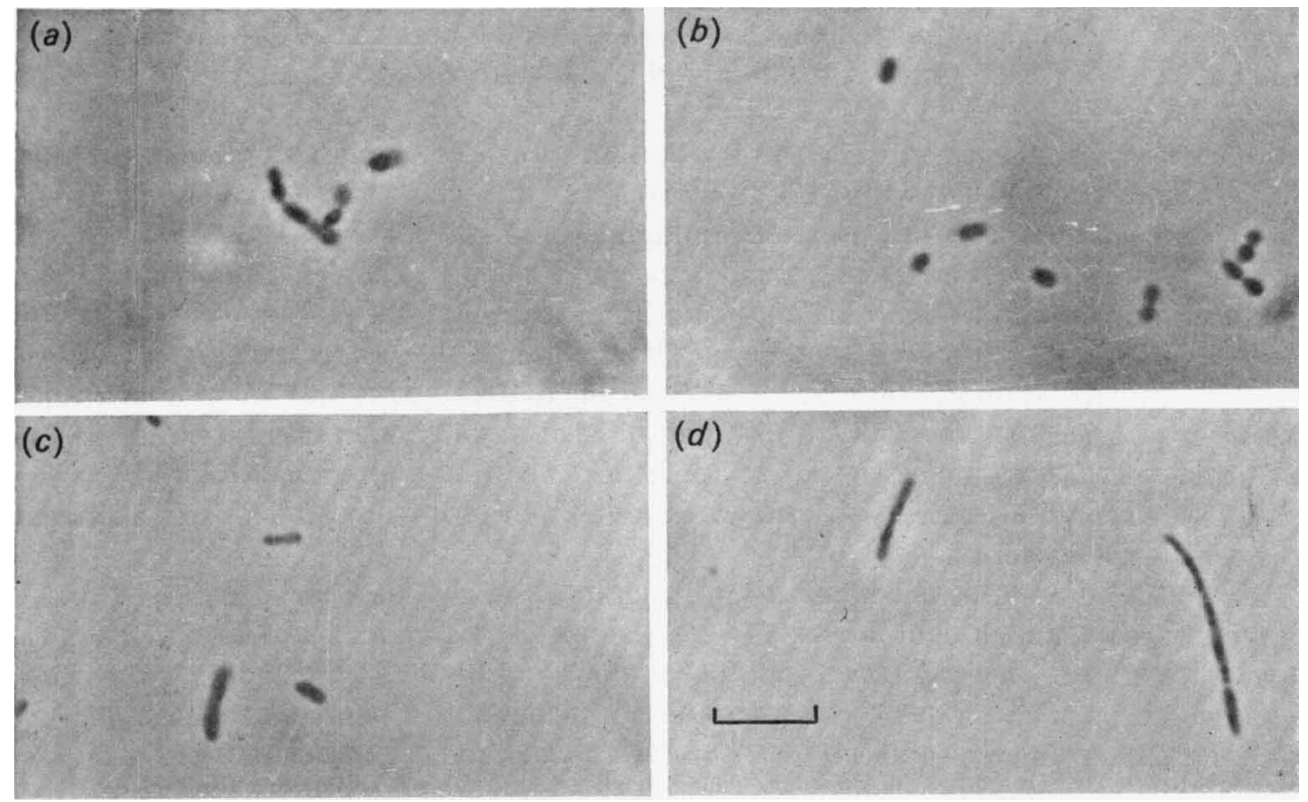

Fig. 4. Modifications to the shape of unadapted mutant cells induced by limiting the oxygen pressure. Cells growing aerobically with oxygen bubbling through the culture $(a)$ were transferred to semi-aerobiosis $\left[\mathrm{N}_{2} / \mathrm{O}_{2}(95: 5, \mathrm{v} / \mathrm{v})\right]$ for two $(b)$ and four $(c)$ generations and then to anaerobiosis with light for three generations $(d)$. Bar marker represents $10 \mu \mathrm{m}$.

the adaptation process (Fig. 3), the filament length was directly proportional to the rate of pigment precursor excretion.

Thus the two phenotypic expressions appeared to be the consequence of the same mutational event. Moreover, the reversion rate of $5 \times 10^{-7}$ indicated that the mutation was a single pleiotropic one. 


\section{Mutational defects}

Analysis of cell envelope proteins. As the construction of the photosynthetic apparatus, as well as cell division, requires synthesis of the cell envelope, we examined the proteins of the envelopes of the wild type and the unadapted mutant using SDS-polyacrylamide gel electrophoresis. Pigmented cells of both strains differed only in the bands representing bacteriochlorophyll holochromes: bands 9, IO, II at the reaction centre and band 15 for the antenna bacteriochlorophyll were markedly stronger in the wild type than in the mutant (Fig. 5a). Depigmented cells from the unadapted mutant and from the wild type showed the same envelope polypeptide composition (Fig. $5 b$ ). However, when the proteins were purified further (centrifuging in a discontinuous gradient of Ficoll), the preparation from bleached mutant cells separated in two fractions. The first was situated, as in the wild-type preparation, between zones of 10 and $20 \%(w / v)$ Ficoll; the second was between zones of 20 and $30 \%(w / v)$ Ficoll.

Thus, except for the polypeptides which are associated with pigment, no appreciable defect in the major classes of polypeptides from the mutant cell envelope was detected. However, the separation of the cell envelope preparation in two fractions of different densities indicated that some modification had occurred. Of two types of mutants of Escherichia coli, one deficient in phospholipid synthesis (McIntyre \& Bell, 1975), and the other in cell envelope proteins (Schweitzer et al., 1976), the former showed an increase in the buoyant density of its membrane and the latter a decrease. The protein/phospholipid ratio was higher in the 'Phofil' mutant than in the parent (Table 2), both in envelope preparations of bleached cells (increase of $52 \%$ ) and in whole cells grown semi-aerobically (increase of $33 \%$ ).

Return to the unadapted state. (i) Intracytoplasmic membrane differentiation. Uspenskaya \& Lyskova (1972) and Drews (1974), using Rhodopseudomonas palustris and Rhodopseudomonas capsulata respectively, isolated mutants whose phenotypes were expressed when pigment synthesis was induced after total or partial bleaching, i.e. after an initial differentiation of intracytoplasmic membrane into cytoplasmic membrane. We studied the differentiation of the intracytoplasmic membrane of adapted mutants of $R$. sphaeroides in two ways: firstly by transfer of photosynthetically-grown cells to aerobiosis; and secondly by transfer of cells grown photosynthetically at low light intensity to high light intensity. In the former case, the typical constituents of intracytoplasmic membrane are utilized for cytoplasmic membrane formation, whereas in the latter case, de novo synthesis of both membranes occurs (Irschik \& Oelze, I973).

Aerobic cultures, grown for up to 25 generations under pure oxygen in the dark or sparged with air in high light intensity, were periodically examined for their repigmentation capacity by transferring samples to photosynthetic conditions. Repigmentation occurred as in the wild type. There was no re-expression of the unadapted phenotype. After 25 generations, the sample stayed completely bleached and was unable to start photosynthetic growth (repigmentation requiring an intermediate transfer in semi-aerobiosis). After transfer from low light intensity under nitrogen $\left(700 \mathrm{~lx}, 6.5 \mathrm{nmol}\right.$ bacteriochlorophyll per $10^{9}$ cells) to high light intensity $\left(6000 \mathrm{~lx}, 2 \cdot 2 \mathrm{nmol}\right.$ bacteriochlorophyll per $\left.10^{9} \mathrm{cells}\right)$, the adapted bacteria were grown again at low light intensity. Repigmentation proceeded without the reappearance of the unadapted phenotype.

Thus, no return to the unadapted phenotype was observed during repigmentation of previously bleached adapted cells, either when the cytoplasmic membrane was derived from functional intracytoplasmic membrane or when synthetized de novo. This conclusion may be extended to the unadapted mutant. The rate of pigment precursor excretion observed in semi-aerobiosis was not significantly different before or after bleaching the inoculum.

(ii) Factors promoting filamentation. Low doses of penicillin inhibit bacterial septation and, as growth proceeds, the cells elongate and from filaments (Strominger et al., 1971). 


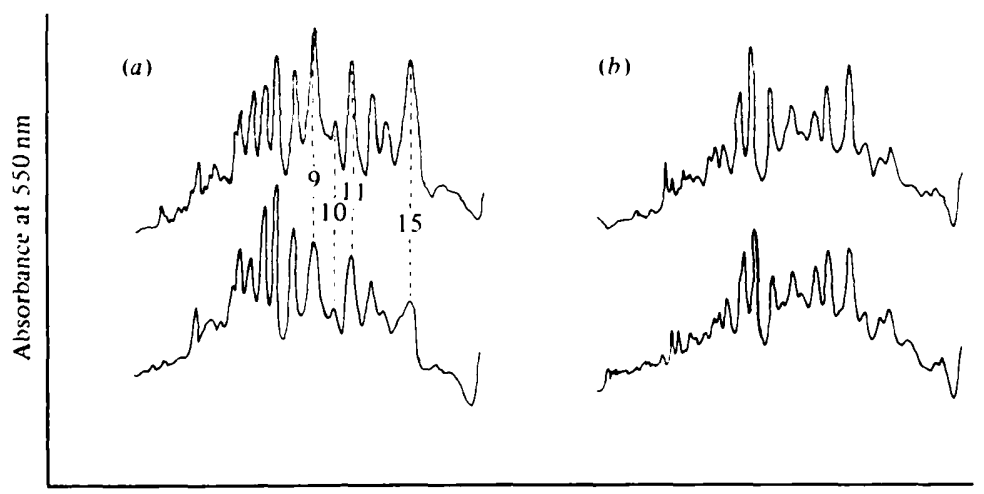

Distance migrated

Fig. 5. SDS-polyacrylamide gel electrophoresis of cell envelope proteins from the wild type (upper trace) and unadapted mutant (lower trace). (a) Semi-aerobiosis $\left[\mathrm{N}_{2} / \mathrm{O}_{2}(95: 5, \mathrm{v} / \mathrm{v})\right] ;($ b) aerobiosis (oxygen). Cell envelopes were isolated, as described in Methods, after centrifuging in $30 \%(\mathrm{w} / \mathrm{v})$ CsCl.

Table 2. Protein/phospholipid ratios $(w / w)$ in the unadapted mutant and the wild type Data for protein normalized to Ioo. Pigmented cells were grown semi-aerobically.

$$
\text { Protein Phospholipid* Protein/phospholipid }
$$

Envelope of bleached cells

Unadapted mutant $\quad 100 \quad 35 \quad 2 \cdot 9$

$\begin{array}{llll}\text { Wild type } & 100 & 52 & 1 \cdot 9\end{array}$

Pigmented cells

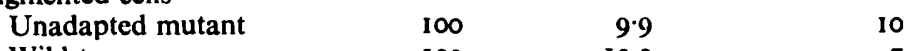

$\begin{array}{llll}\text { Wild type } & 100 & 13.2 & 7.5\end{array}$

- Determined by phosphate analysis, assuming an average molecular weight of 750 .

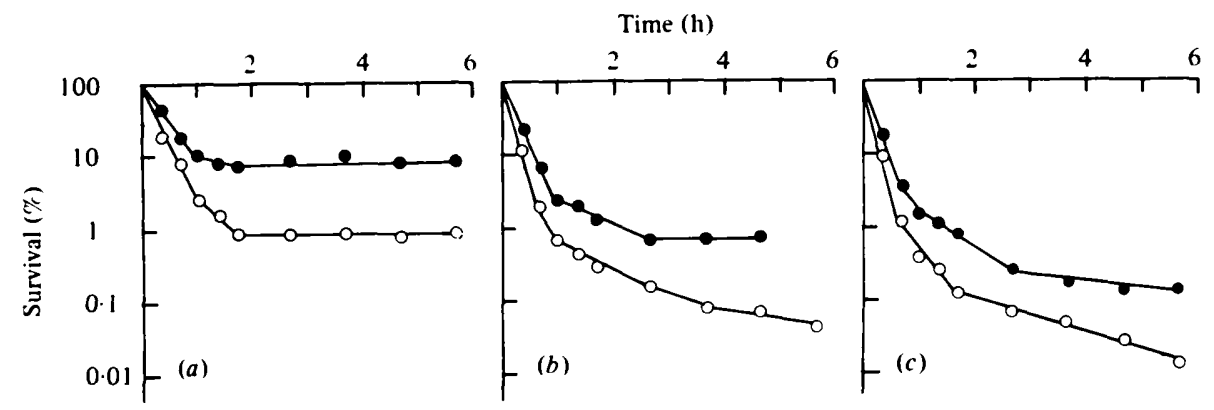

Fig. 6. Survival kinetics of unadapted mutant $(\bullet)$ and wild-type $(O)$ strains grown in semi-aerobic conditions with penicillin at: (a) 100 units $\mathrm{ml}^{-1},(b) 200$ units $\mathrm{ml}^{-1}$, (c) 500 units $\mathrm{ml}^{-1}$. Data corrected for the corresponding growth of control. Ratios of initial slopes (mutant/wild type) are (a) I. $50,(b)$ I.50, (c) I. 45 .

Penicillin induced filamentation in adapted $R$. sphaeroides but the pigment precursor was not excreted. Nevertheless, the death rate of the mutant was lower than that of the wild type. The survival curves (Fig. 6) were clearly polyphasic; as the time of the experiment exceeded the doubling time, the data were corrected for the ensuing growth. The ratio of the initial slopes of the curves (mutant/wild type) had a constant value of $I \cdot 5$ whatever the antibiotic concentration. This indicates a higher resistance of the mutant. The second parts of 
the curves showed increasing slopes up to infinity (Fig. $6 a, b$ ); the surviving cells then grew like the control.

Ultraviolet light induces filamentation in several mutants of heterotrophic bacteria (Walker \& Pardee, 1967). Rhodopseudomonas sphaeroides grown semi-aerobically was irradiated during the exponential growth phase: the dose-effect curves of the wild type and the adapted mutant were similar; the survival of unadapted mutant cells was appreciably higher (Fig. 7a), probably due to their polyploidy in semi-aerobiosis. Examination of the colonies obtained from surviving adapted mutants indicated that the unadapted phenotype was not expressed. When adapted mutant cells from a culture growing exponentially and semi-aerobically at $30^{\circ} \mathrm{C}$ were left for $6 \mathrm{~h}$ at ambient temperature $\left(20^{\circ} \mathrm{C}\right)$ before irradiation, a quantitatively significant number of survivors, depending on the dose given, gave colonies with the unadapted phenotype (Fig. $7 b$ ). No heterogeneity was observed among the colonies obtained ( 1500 in number) from non-irradiated (reference) or weakly irradiated $\left(20 \mathrm{~J} \mathrm{~m}^{-2}\right)$ cells. The results cannot therefore be due to an initial heterogeneity in the culture, such as a mixture of adapted and unadapted cells, which would lead (as the unadapted cells have a lower sensitivity) to selective death of adapted mutant cells. The two latter observations on the effect of ultraviolet light irradiation on exponentially growing cells either at $30^{\circ} \mathrm{C}$ or after transfer to $20^{\circ} \mathrm{C}$, are not necessarily contradictory. The results were analysed only after a time equivalent to 30 generations, as required for colony formation; even if the surviving cells had resumed the unadapted phenotype, their descendants might have recovered a corrected phenotype during this period.

The influence of low temperature was demonstrated when an inoculum was taken from an adapted culture and grown aerobically at $2 \mathrm{I}{ }^{\circ} \mathrm{C}$ and samples were transferred to photosynthetic conditions at $30^{\circ} \mathrm{C}$. Repigmentation of samples taken during the exponential growth phase at $2 \mathrm{I}^{\circ} \mathrm{C}$ was similar to that of the wild type. On the other hand, both phenotypes appeared during the repigmentation of samples from the stationary phase. Hence, two conditions, ultraviolet light and low temperature, have been found which promote the reappearance of the unadapted phenotype.

\section{DISCUSSION}

Cell division mutants fall into two categories: in one type, the synthesis of DNA is affected together with septation; in the other, DNA synthesis proceeds, with apparently normal segregation as the cells elongate (Slater \& Schaechter, 1974). The 'Phofil' mutant (Fig. I) clearly belongs to the latter group. The cell envelope is currently thought to play an important role in the control of bacterial cell division. Alterations in the wall (Stone, 1973) or in the cytoplasmic membrane (Starka, 1971; Slater \& Schaechter, 1974) may impair septation. Our evidence strongly suggests the presence of a defect in the wall as well as in the cytoplasmic membrane of the 'Phofil' mutant.

The molecular weight of the smallest unit of the excreted complex was 24000 to 28000 , as determined by the ponderal partition (half to half) between the proteinaceous and nonproteinaceous parts and by analysis of the polypeptide composition (one polypeptide had a mol. wt of 12000 to 14000 ; unpublished work). The excretion of such a large complex indicated that the cell wall was defective (Leive, 1974). Moreover, structural anomalies in the wall of the filaments were clearly visible (Fig. I $b$ ). Further evidence supporting this view was shown by the different effects of $\mathrm{NaCl}$ and sucrose. The inhibition of division of unadapted cells grown photosynthetically was reversed by $\mathrm{NaCl}(0.25 \mathrm{M})$ but not by sucrose at the same concentration. Stone (1973) noted the same behaviour with a division mutant of $E$. coli and suggested that, since sucrose was ineffective, $\mathrm{NaCl}$ did not act on the cytoplasmic membrane by increasing the osmolarity but that the conformation of the cell wall might be stabilized or otherwise modified by direct interaction with the electrolyte.

The assumption of the existence of a defect in the inner membrane is based firstly on the 

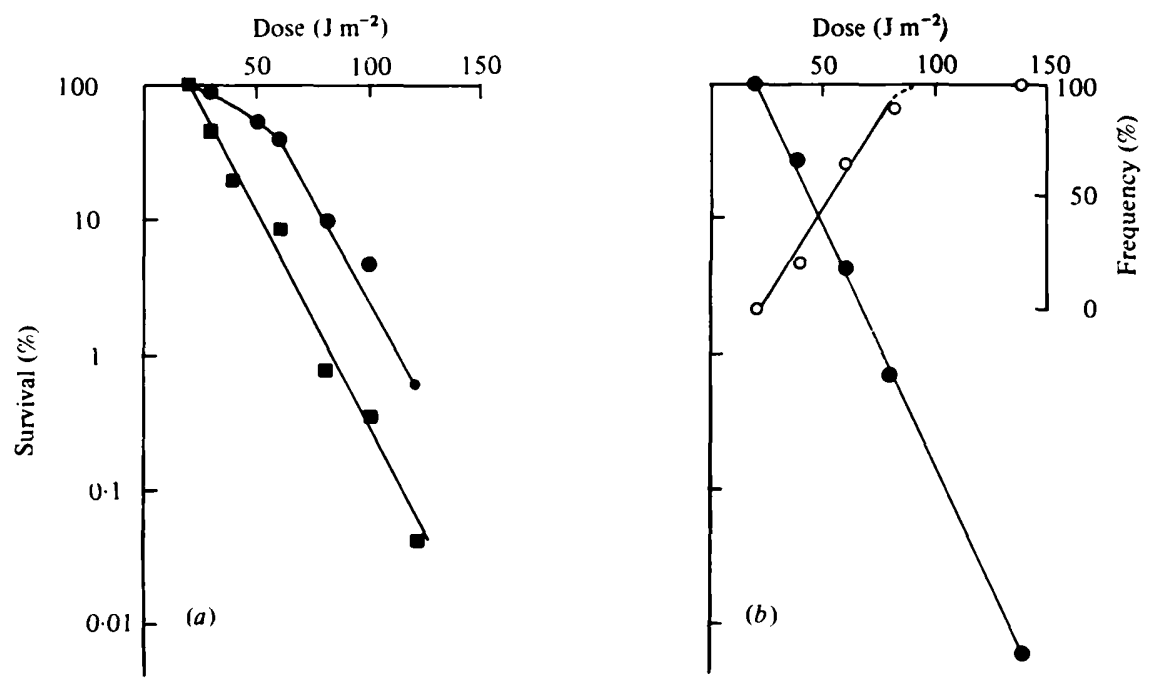

Fig. 7. Effect of ultraviolet light irradiation on the viability of $(a)$ unadapted mutant $(O)$ and wildtype $(\square)$ cells (survivals of wild type and adapted mutant cells were identical), and $(b)$ adapted cells left in suspension for $6 \mathrm{~h}$ at $20^{\circ} \mathrm{C}$ prior to irradiation (O); frequency of colonies with unadapted phenotype among survivors $(O)$ calculated after examining 500 to 1000 colonies.

relative inability of this membrane to incorporate the pigment complexes synthetized, particularly the last precursor $F_{790}$ bacteriochlorophyll(ide) complex (Pradel \& Clément-Métral, 1976), and secondly on the higher tolerance of the mutant towards penicillin. Such a tolerance cannot be attributed to a decreased ability of the antibiotic to enter the cell, as the wall shows a defective barrier function, but rather to a restriction of the rate at which penicillin can reach its target. Recent work of Spratt \& Pardee (1975) indicates that all the penicillinbinding proteins are in the cytoplasmic membrane and that one is an enzyme involved in the terminal stages of peptidoglycan metabolism. Thus, an alteration of the cytoplasmic membrane could affect the function of this enzyme leading simultaneously to higher resistance to penicillin and to a deficient peptidoglycan layer of the cell wall. The protein/phospholipid ratio and the qualitative analysis of polypeptides by gel electrophoresis suggest that the membrane of the mutant is defective in phospholipids rather than in polypeptides.

As the unadapted phenotype is not expressed after bleaching adapted cells, the mutation is not in the photosynthetic apparatus itself. The positive actions of low temperature and ultraviolet light irradiation suggest instead that the disturbed adaptation process corresponds to a period of unbalanced growth (Normark \& Wolf-Watz, 1974). During this unbalanced growth the different layers of the cell envelope are defective in several functions: diffusion barrier, structural integrity, cell division and photosynthetic apparatus construction.

During the disturbed adaptation of the 'Phofil' mutant, the inner membrane differentiates only to a certain extent, the degree of differentiation being representative of the degree of adaptation of the inoculum. The reverse process, i.e. loss of pigmentation by transfer from anaerobic to aerobic conditions, induces no or little modification of this degree of adaptation. Thus, bleached mutant cultures can be obtained with different potentials for cytoplasmic membrane differentiation. This property, which permits the study of the assembly of photopigments in various, and particularly low, levels of membrane differentiation, will be examined further.

We thank F. Espardellier for the constructive criticism of the manuscript and C. Astier for her valuable assistance during survival tests with penicillin. 


\section{REFERENCES}

Barlett, G. R. (1959). Phosphorus assay in column chromatography. Journal of Biological Chemistry 234, 466-468.

Clayton, R. K. (1963). Absorption spectra of photosynthetic bacteria and their chlorophylls. In Bacterial Photosynthesis, pp. 498-500. Edited by H. Gest, A. San Pietro and L. P. Vernon. Yellow Springs, Ohio: Antioch Press.

Clayton, R. K. \& Haselkorn, R. (1972). Protein components of bacterial photosynthetic membranes. Journal of Molecular Biology 68, 95-105.

Cohen-Bazire, G., Sistrom, W. R. \& Stanier, R. Y. (1957). Kinetic studies of pigment synthesis by non-sulfur purple bacteria. Journal of Cellular and Comparative Physiology 49, 25-68.

Drews, G. (1974). Composition of a protochlorophyll-protopheophytin complex, excreted by mutant strains of Rhodopseudomonas capsulata, in comparison with the photosynthetic apparatus. Archives of Microbiology 100, 397-407.

IRSCHIK, H. \& OELzE, J. (I973). Membrane differentiation in phototrophically growing Rhodospirillum rubrum during transition from low to high light intensity. Biochimica et biophysica acta 330, 80-89.

Jolchine, G. \& Reiss-Husson, F. (1974). Comparatives studies on two reaction center preparations from Rhodopseudomonas spheroides. FEBS Letters 40, 5-8.

KATES, M. (1972). Lipid extraction procedures. In Techniques in Lipodology, pp. 347-353. Edited by T. S. Work and E. Work. Amsterdam: North Holland Publishing Company.

LAEMMLI, U. K. (1970). Cleavage of structural proteins during the assembly of the head of bacteriophage $T_{4}$. Nature, London 227, 680-685.

Latarjet, R., Morenne, P. \& Berger, R. (1953). Un appareil simple pour le dosage des rayonnements ultra-violets émis par les lampes germicides. Annales de l'Institut Pasteur 85, 174-178.

LEIVE, L. (1974). The barrier function of the gramnegative envelope. Annals of the New York Academy of Sciences 235, 109-129.

Lowry, O. H., Roserrough, N. J., FArR, A. L. \& Randall, R. J. (1951). Protein measurement with the Folin phenol reagent. Journal of Biological Chemistry r93, 265-275.

MCINTYRe, T. M. \& Bell, R. M. (1975). Mutant of Escherichia coli defective in membrane phospholipid synthesis. Effect of cessation of net phospholipid synthesis on cytoplasmic and outer membrane. Journal of Biological Chemistry 250, 9053-9059.

Niederman, R. A., Mallon, D. E. \& Langan, J. J. (1976). Membrane of Rhodopseudomonas spheroides. IV. Assembly of chromatophores in lowaeration cell suspension. Biochimica et biophysica acta 440, 429-447.
Normark, S. \& Wolf-WATZ, H. (I974). Cell division and permeability of unbalanced envelope mutants of Escherichia coli. Annales de Microbiologie (Institut Pasteur) 125B, 2 I I-226.

Oelze, J. \& Drews, G. (1972). Membranes of photosynthetic bacteria. Biochimica et biophysica acta 265, 209-239.

Oelze, J. \& PahlKe, W. (1976). The early formation of the photosynthetic apparatus in Rhodospirillum rubrum. Archives of Microbiology 108, 28 I-285.

Peters, G. A. \& Cellarius, R. A. (1972). Photosynthetic membrane development in Rhodopseudomonas spheroides. II. Correlation of pigment incorporation with morphological aspects of thylakoid formation. Bioenergetics 3, 345-359.

Pradel, J. \& Clément-Métral, J. (1976). A 4-vinylprotochlorophyllide complex accumulated by 'Phofil' mutant of Rhodopsendomonas spheroides. An authentic intermediate in the development of the photosynthetic apparatus. Biochimica et biophysica acta 430, 253-264.

Saunders, V. A. \& Jones, O. T. G. (1974). Adaptation in Rhodopseudomonas spheroides. FEBS Letters 44, 169-172.

Schweitzer, M., Schwarz, H., Sonntag, I. \& HeNNING, U. (1976). Mutational change of membrane architecture. Mutants of Escherichia coli KI2 missing major proteins of the outer cell envelope membrane. Biochimica et biophysica acta 448, 474-49I.

Slater, M. \& Schaechter, M. (1974). Control of cell division in bacteria. Bacteriological Reviews 38, 199-22 I.

Spratt, B. G. \& Pardee, A. B. (1975). Penicillinbinding proteins and cell shape in Escherichia coli. Nature, London 254, 516-517.

Starka, J. ( 197I). Cell envelope proteins of dividing and non dividing cells of Escherichia coli. FEBS Letters 16, 223-225.

Stone, A. B. (1973). Regulation of cell division in a temperature-sensitive division mutant of Escherichia coli. Journal of Bacteriology 116, 741-750.

Strominger, J. L., Blumberg, P. H., Suginaka, H. \& UMBreIT, J. (1971). How penicillin kills bacteria: progress and problems. Proceedings of the Royal Society Br79, 267-276.

TAKemoro, J. \& LASCelles, J. (1973). Coupling between bacteriochlorophyll and membrane protein synthesis in Rhodopseudomonas spheroides. Proceedings of the National Academy of Sciences of the United States of America 70, 799-803.

USPENSKAYA, V. E. \& LYSKOVA, G. V. (1972). Synthesis of pigments by the mutant of Rhodopseudomonas palustris under different growth conditions. Mikrobiologiya 6, $1038-1044$.

Walker, J. R. \& Pardee, A. B. (1967). Conditional mutations involving septum formation in Escherichia coli. Journal of Bacteriology 93, 107-1 14. 